\title{
Dehydrogenation of Methanol by Vanadium Oxide and Hydroxide Cluster Cations in the Gas Phase
}

\author{
Sandra Feyel, ${ }^{\dagger}$ Ludwig Scharfenberg, ${ }^{\ddagger}$ Charles Daniel, ${ }^{\S}$ Hans Hartl, ${ }^{\S}$ Detlef Schröder, ${ }^{*, l l}$ and \\ Helmut Schwarz ${ }^{*} \dagger$ \\ Institut für Chemie der Technischen Universität Berlin, Strasse des 17. Juni 135, D-10623 Berlin, Germany, \\ Fritz-Haber-Institut der Max-Planck-Gesellschaft, Faradayweg 4-6, 14195 Berlin, Germany, Anorganische und \\ Analytische Chemie, Freie Universität Berlin, Fabeckstrasse 34-36, 14195 Berlin, Germany, and Institute of \\ Organic Chemistry and Biochemistry, Academy of Sciences of the Czech Republic, Flemingovo nám. 2, \\ 16610 Praha 6, Czech Republic
}

Received: November 10, 2006; In Final Form: January 23, 2007

\begin{abstract}
Bare vanadium oxide and hydroxide cluster cations, $\mathrm{V}_{m} \mathrm{O}_{n}{ }^{+}$and $\mathrm{V}_{m} \mathrm{O}_{n-1}(\mathrm{OH})^{+}(m=1-4, n=1-10)$, generated by electrospray ionization, were investigated with respect to their reactivity toward methanol using mass spectrometric techniques. Several reaction channels were observed, such as abstraction of a hydrogen atom, a methyl radical, or a hydroxymethyl radical, elimination of methane, and adduct formation. Moreover, dehydrogenation of methanol to generate formaldehyde was found to occur via four different pathways. Formaldehyde was released as a free molecule either upon transfer of two hydrogen atoms to the cluster or upon transfer of an oxygen atom from the cluster to the neutral alcohol concomitant with elimination of water. Further, formaldehyde was attached to $\mathrm{V}_{m} \mathrm{O}_{n}{ }^{+}$upon loss of $\mathrm{H}_{2}$ or neutral water to produce the cation $\mathrm{V}_{m} \mathrm{O}_{n}\left(\mathrm{OCH}_{2}\right)^{+}$or $\mathrm{V}_{m} \mathrm{O}_{n-1}\left(\mathrm{OCH}_{2}\right)^{+}$, respectively. A reactivity screening revealed that only high-valent vanadium oxide clusters are reactive with respect to $\mathrm{H}_{2}$ uptake, oxygen transfer, and elimination of $\mathrm{H}_{2} \mathrm{O}$, whereas smaller and low-valent cluster cations are capable of dehydrogenating methanol via elimination of $\mathrm{H}_{2}$. For comparison, the reactivity of methanol with the corresponding hydroxide cluster ions, $\mathrm{V}_{m} \mathrm{O}_{n-1}(\mathrm{OH})^{+}$, was studied also, for which dominant pathways lead to both condensation and association products, i.e., generation of the ions $\mathrm{V}_{m} \mathrm{O}_{n-1}\left(\mathrm{OCH}_{3}\right)^{+}$and $\mathrm{V}_{m} \mathrm{O}_{n-1}(\mathrm{OH})\left(\mathrm{CH}_{3} \mathrm{OH}\right)^{+}$, respectively.
\end{abstract}

\section{Introduction}

In the forthcoming decades, a new era for commercial usage of energy will inevitably begin. One reason for this change, among others, is the global warming that we are currently witnessing. With recent crude oil prices of about $\$ 70$ (U.S.) per barrel, the world economy faces limitations, because both producers and consumers tighten theirs belts in the expectation of even higher prices in the future. Obviously, mankind urgently needs to find a way out of the oil era. In this respect, the use of methanol provides an alternative solution to conventional motor fuels. ${ }^{1}$ Further, this compound can be used in various ways as a substitute for oil, e.g., in $\mathrm{H}_{2}$ fuel cells or in the synthesis of more valuable compounds such as formaldehyde, dimethylether, methyl-t-butylether, and even biodiesel. As methanol can be made from various fossil and biogenous raw materials, the available resources are almost unlimited.

Vanadium oxides are an important class of transition-metal catalysts for oxidative dehydrogenation (ODH) processes. The dehydrogenation of methanol by gaseous vanadium oxide clusters has already been studied both theoretically ${ }^{2-4}$ and experimentally ${ }^{5-11}$ to obtain information about structure/reactivity correlations, cluster-size effects, and the role of formal and

* Corresponding authors. Fax: +420 220183583 (D.S.), +49 30314 21102 (H.S.). E-mail: Detlef.Schroeder@uochb.cas.cz (D.S.), Helmut.Schwarz@mail.chem.tu-berlin.de (H.S.).

$\dagger$ Institut für Chemie der Technischen Universität Berlin.

Fritz-Haber-Institut der Max-Planck-Gesellschaft.

$\S$ Freie Universität Berlin.

"Academy of Sciences of the Czech Republic. real charge states. With respect to the gas-phase dehydrogenation of methanol by mononuclear vanadium oxide cations, the valence of the metal has been shown to act as a decisive factor. ${ }^{5}$ Cations in low oxidation states (i.e., $\mathrm{V}^{+}$and $\mathrm{VOH}^{+}$) reduce methanol to methane, whereas $\mathrm{VO}_{2}{ }^{+}$mediates an oxidative dehydrogenation to formaldehyde. $\mathrm{VO}^{+}$also dehydrogenates methanol, but in the monoxide cation, the metal does not change oxidation state during the entire course of the reaction. ${ }^{5 a}$ Although these findings are of interest in their own right, mononuclear metal oxides are by no means an ideal model systems for the modeling of real oxidation catalysts, and thus, an advanced understanding of the reactions of metal oxide clusters is desirable.

The reactivity of vanadium oxide and hydroxide cluster cations with respect to the dehydrogenation of small alkenes has already been investigated. ${ }^{12,13}$ Studies of ion-molecule reactions (IMRs) of mass-selected $\mathrm{V}_{m} \mathrm{O}_{n}{ }^{+}$and $\mathrm{V}_{m} \mathrm{O}_{n-1}(\mathrm{OH})^{+}$ cations with isomeric butenes have suggested that high-valent clusters prefer oxidative dehydrogenation concomitant with addition of two hydrogen atoms to the cluster and elimination of neutral butadiene. ${ }^{13}$ In contrast, low-valent clusters tend to add the diene concomitant with loss of molecular hydrogen. In continuation of these studies, the present contribution describes the reactivity of vanadium oxide and hydroxide cluster cations toward methanol with particular attention to ODH activity and the role of the formal valence of the metal atoms.

\section{Experimental Methods}

Ion-molecule reactions were investigated using a VG BIO-Q mass spectrometer that consists of an electrospray ionization 
(ESI) source combined with a tandem mass spectrometer of QHQ configuration $(\mathrm{Q}=$ quadrupole, $\mathrm{H}=$ hexapole $) .{ }^{14}$ The hexanuclear methoxo-oxovanadium cluster $\mathrm{V}_{6} \mathrm{O}_{7}\left(\mathrm{OCH}_{3}\right)_{12}$ used as precursor compound ${ }^{15}$ was dissolved in $\mathrm{CD}_{3} \mathrm{OD}$ and sprayed under harsh ESI conditions to obtain the smaller vanadium oxide clusters $\mathrm{V}_{m} \mathrm{O}_{n}{ }^{+}$and the oxovanadium hydroxide clusters $\mathrm{V}_{m} \mathrm{O}_{n-1}(\mathrm{OD})^{+}(m=1-4, n=1-10)$, as described elsewhere in detail. ${ }^{13,16}$ To this end, the solution of the precursor was introduced into the ESI source using fused silica tubing $(75 \mu \mathrm{m}$ i.d.) at a flow rate of about $5 \mu \mathrm{L} / \mathrm{min}$ and a source temperature of $90{ }^{\circ} \mathrm{C}$. The cone voltage was kept at about $190 \mathrm{~V}$ to maximize the fragmentation of the precursor in order to increase the signals of the desired smaller clusters. ${ }^{16}$ All data were collected and averaged over at least 20, and for weaker signals up to 100 , scans. The bimolecular reactivities of the respective massselected cluster ions toward methanol were studied by introducing the alcohol at pressures of $0.5-4 \times 10^{-4} \mathrm{mbar}$ (in one case, up to $10^{-3}$ mbar; see below).

A peculiarity of the present system arises from the fact that dioxygen and methanol have the same nominal mass (both 32 amu) and thus can give rise to isobaric interferences. Given the limited mass resolution of quadrupole-based mass spectrometers, ${ }^{17}$ characterization and generation of pure vanadium clusters is therefore more difficult, as they can contain isobaric oxo- and/or methanol ligands. Exchange of the methoxo ligands in the precursor molecule $\mathrm{V}_{6} \mathrm{O}_{7}\left(\mathrm{OCH}_{3}\right)_{12}$ to $\mathrm{OCD}_{3}$ groups circumvents this ambiguity, because the signals of the complexes with oxo ligands are no longer isobaric with those containing methanol. Consequently, the data for the vanadium hydroxide cluster cations discussed below in fact refer to $\mathrm{V}_{m} \mathrm{O}_{n-1}(\mathrm{OD})^{+}$ cations. ${ }^{16}$ Nevertheless, some of the generated labeled dinuclear vanadium oxide cations show overlaps with components containing $\mathrm{CD}_{3} \mathrm{OD}$ and $\mathrm{N}_{2}$ (nebulizing gas), as indicated in the reactivity studies reported below by the observed mass differences of $\Delta m=-4,+4$, and +13 , which are assigned to substitution of a $\mathrm{CD}_{3} \mathrm{OD}$ ligand by $\mathrm{CH}_{3} \mathrm{OH}$, substitution of a loosely bound $\mathrm{N}_{2}$ molecule by $\mathrm{CH}_{3} \mathrm{OH}$, and generation of dimethoxo cluster cations concomitant with elimination of HDO, respectively. Further, some of the generated oxovanadium hydroxide cluster cations overlap with small amounts of $\mathrm{V}_{m} \mathrm{O}_{n-2}\left(\mathrm{OCD}_{3}\right)^{+}$ions, as indicated by loss of three mass units in the reaction with $\mathrm{CH}_{3} \mathrm{OH}$ (replacement of $\mathrm{OCD}_{3}$ by $\mathrm{OCH}_{3}$ ). These assignments are based on careful inspection of the isotope patterns in the ESI mass spectra in series of experiments with $\mathrm{CH}_{3} \mathrm{OH},{ }^{13} \mathrm{CH}_{3} \mathrm{OH}, \mathrm{CH}_{3}{ }^{18} \mathrm{OH}$, and $\mathrm{CD}_{3} \mathrm{OD}$. Involvement of $\mathrm{CO}$ rather than $\mathrm{N}_{2}$, for example, can be excluded by experiments with ${ }^{13} \mathrm{CH}_{3} \mathrm{OH}$ and $\mathrm{CH}_{3}{ }^{18} \mathrm{OH}$.

As described below, several secondary reactions were also observed, and on several occasions, the pressure of methanol serving as the neutral reaction partner was deliberately elevated above the single-collision regime in order to investigate the consecutive reaction sequences occurring. In the evaluation of the branching ratios (BRs) for the primary reactions, these secondary products were accordingly added to the BRs of the respective primary reaction products.

All unlabeled and labeled reagents were used as purchased and were introduced into the mass spectrometer by conventional vacuum techniques. Deuteration of $\mathrm{V}_{6} \mathrm{O}_{7}\left(\mathrm{OCH}_{3}\right)_{12}$ was achieved by simple dissolution of the precursor in a 100-fold excess of $\mathrm{CD}_{3} \mathrm{OD}$ followed by 1 week of storage at ambient temperature. After this treatment, more than $95 \%$ deuteration was achieved, as determined by ESI mass spectrometry. ${ }^{13,16}$

\section{Results and Discussion}

In the present work, ESI was used to generate mono-, di-, tri-, and tetranuclear vanadium oxide and hydroxide cluster cations in the gas phase, and the bimolecular reactivities of these species toward methanol were then studied. The focus of this article is the dehydrogenation activity of various vanadium oxide and hydroxide cluster cations having the general formulas $\mathrm{V}_{m} \mathrm{O}_{n}{ }^{+}$and $\mathrm{V}_{m} \mathrm{O}_{n-1}(\mathrm{OD})^{+}(m=2-4, n=$ $2-10)$ and covering average formal oxidation states of vanadium from 2.00 to $5.25 .{ }^{18}$ For comparison, the findings obtained for the well-investigated mononuclear vanadium species are also included..$^{5}$ As mentioned above, the reactivity of these vanadium oxide cluster ions toward isomeric butenes and small alkanes has already been examined, and a strong dependence of the product distribution on the oxidation state of vanadium was found. ${ }^{13}$ This result accordingly raises the question as to whether similar trends arise in the dehydrogenation of methanol.

Binary Vanadium Oxides. The mass differences and production branching ratios observed in the reactions of mass-selected vanadium oxide cluster cations with neutral methanol are summarized in Table 1. In addition, the relative rate constants $\left(k_{\text {rel }}\right)$ and the formal valence $(\mathrm{fv})$ values of vanadium in the cluster ions are given. In the latter quantity, each oxygen atom is regarded as a formal $\mathrm{O}^{2-}$ ligand, such that the number of oxygen atoms, $N_{\mathrm{O}}$, and the monopositive charge determine the average valence of vanadium as $f v=\left(2 N_{\mathrm{O}}+1\right) / N_{\mathrm{V}}$, where $N_{\mathrm{V}}$ represents the number of vanadium atoms in the cluster. This simple approach often yields noninteger valences, and we explicitly note that (i) the notation shall neither indicate nor exclude mixed-valence states and (ii) the counting scheme can lead to valences larger than $\mathrm{V}(\mathrm{V})$ in the case of oxygen-centered radicals, because the formalism treats all oxygen atoms as genuine $\mathrm{O}^{2-}$ ligands, irrespective of the actual bonding situations.

The product patterns observed in the reactions of $\mathrm{V}_{m} \mathrm{O}_{n}{ }^{+}$ clusters with methanol (Table 1) can be grouped into four different categories.

(i) Several processes occur that can be attributed to the production of formaldehyde. A net oxygen-atom transfer from the cluster to the neutral reagent takes place $(\Delta m=-16),{ }^{19}$ which is most likely associated with formation of $\mathrm{CH}_{2} \mathrm{O}+\mathrm{H}_{2} \mathrm{O}$ as two separate neutral products (ODH1). Formal uptake of two hydrogen atoms by the cluster $(\Delta m=+2)$ affords the corresponding ions $\mathrm{V}_{m} \mathrm{O}_{n-2}(\mathrm{OH})_{2}{ }^{+}$together with neutral formaldehyde (ODH2). Loss of water from the cluster can occur after the addition of methanol $(\Delta m=+14$; ODH3). The complementary release of neutral dihydrogen with formaldehyde remaining bound to the cluster ion $(\Delta m=+30)^{20}$ can be classified as dehydrogenation (DH), because vanadium does not need to change oxidation state in the overall process (Scheme 1).

(ii) In a number of abstraction reactions, open-shell species are released, i.e., abstraction of atomic hydrogen $(\Delta m=+1)$, a methyl radical $(\Delta m=+15)$, a hydroxy group $(\Delta m=+17)$, or a $\left[\mathrm{CH}_{3} \mathrm{O}\right]$ unit $(\Delta m=+31)$. The two former processes were observed only for the high-valent tetranuclear clusters, whereas the abstractions of the oxygen-containing moieties $\mathrm{HO}$ and $\left[\mathrm{CH}_{3} \mathrm{O}\right]$ were most pronounced for low-valent cluster ions; throughout this work, the notation $\left[\mathrm{CH}_{3} \mathrm{O}\right]$ represents a radical having this composition that might be either a methoxy radical, $\mathrm{CH}_{3} \mathrm{O}^{\bullet}$, or the thermochemically more stable ${ }^{22}$ hydroxymethyl radical, $\mathrm{CH}_{2} \mathrm{OH}^{\circ}$. 
TABLE 1: Mass Differences $\left(\Delta m\right.$ in amu), Branching Ratios (BR with $\left.\sum \mathbf{B R}_{i}=100\right)$, Relative Rate Constants $\left(k_{\text {rel }}\right)$, and Formal Valence (fv) Values of the Vanadium Atoms in the Clusters in the Ion-Molecule Reactions of $\mathrm{V}_{m} \mathrm{O}_{n}{ }^{+}$Cations with Methanol

\begin{tabular}{|c|c|c|c|c|c|c|c|c|c|c|c|c|}
\hline \multirow[b]{2}{*}{$\mathrm{V}_{m} \mathrm{O}_{n}^{+}$} & \multirow[b]{2}{*}{$k_{\mathrm{rel}}^{a}$} & \multirow[b]{2}{*}{$\mathrm{fv}$} & \multicolumn{10}{|c|}{$\Delta m$} \\
\hline & & & -16 & +1 & +2 & +14 & +15 & +16 & +17 & +30 & +31 & +32 \\
\hline $\mathrm{VO}^{+c}$ & 6 & 3.00 & & & & & & 10 & & 90 & & $b$ \\
\hline $\mathrm{VO}_{2}^{+}$ & 23 & 5.00 & & & 67 & 14 & & 14 & & 5 & & \\
\hline $\mathrm{V}_{2} \mathrm{O}_{2}^{+}$ & 23 & 2.50 & & & & & & 10 & 45 & 5 & 25 & 15 \\
\hline $\mathrm{V}_{2} \mathrm{O}_{3}+c$ & 47 & 3.50 & & & 1 & 1 & & 20 & 38 & 2 & 20 & 18 \\
\hline $\mathrm{V}_{2} \mathrm{O}_{4}^{+}$ & 38 & 4.50 & & & 68 & 4 & & 8 & & 10 & & 10 \\
\hline $\mathrm{V}_{3} \mathrm{O}_{4}^{+}$ & 46 & 3.00 & & & & & & 2 & 2 & & & 96 \\
\hline $\mathrm{V}_{3} \mathrm{O}_{5}+d$ & 53 & 3.67 & & & & & & 5 & 15 & & 5 & 75 \\
\hline $\mathrm{V}_{3} \mathrm{O}_{6}{ }^{+}$ & 65 & 4.33 & 12 & & 38 & & & & 5 & & & 45 \\
\hline $\mathrm{V}_{3} \mathrm{O}_{7}^{+}$ & 40 & 5.00 & 12 & & 26 & 2 & & 5 & & & & 55 \\
\hline $\mathrm{V}_{4} \mathrm{O}_{6}{ }^{+}$ & 27 & 3.25 & & & & & & & & & & 100 \\
\hline $\mathrm{V}_{4} \mathrm{O}_{7}{ }^{+}$ & 68 & 3.75 & & & & & & 2 & & & & 98 \\
\hline $\mathrm{V}_{4} \mathrm{O}_{8}^{+}$ & 100 & 4.25 & 5 & & 1 & & & 2 & 2 & & & 90 \\
\hline $\mathrm{V}_{4} \mathrm{O}_{9}^{+}$ & 74 & 4.75 & 8 & 1 & 10 & & & 1 & & & & 80 \\
\hline $\mathrm{V}_{4} \mathrm{O}_{10}{ }^{+}$ & 58 & 5.25 & 45 & 8 & 23 & 8 & 6 & & & & & 10 \\
\hline
\end{tabular}

${ }^{a}$ Using the previously determined absolute rate constant of the reaction of $\mathrm{VO}^{+}$with methanol $\left[k_{\mathrm{abs}}=(1.2 \pm 0.4) \times 10^{-10} \mathrm{~cm}^{3} \mathrm{molecule} \mathrm{e}^{-1} \mathrm{~s}^{-1}\right.$, ref 5) as an anchor point. $k_{\text {rel }}=100$ corresponds to $k_{\text {abs }}=(5.0 \pm 1.5) \times 10^{-10} \mathrm{~cm}^{3}$ molecule ${ }^{-1} \mathrm{~s}^{-1} \cdot{ }^{b} \mathrm{The}^{-}$formal adduct $\mathrm{OV}\left(\mathrm{CH}_{3} \mathrm{OH}\right)^{+}$is formed in a rapid consecutive reaction via ligand exchange of the primary product $\mathrm{OV}\left(\mathrm{CH}_{2} \mathrm{O}\right)^{+}(\Delta m=+30)$ with neutral methanol; see ref 5. ${ }^{c} \mathrm{IMR}$ of $\mathrm{VO}^{+}$and $\mathrm{V}_{2} \mathrm{O}_{3}{ }^{+}$with methanol also resulted in the formal transfer of a water molecule to the cluster $(\Delta m=+18)$ to afford $\mathrm{V}(\mathrm{OH})_{2}{ }^{+}(\mathrm{BR}=5)$ and $\mathrm{V}_{2} \mathrm{O}_{2}(\mathrm{OH})_{2}{ }^{+}(\mathrm{BR}=9)$. Because direct loss of a $\mathrm{CH}_{2}$ fragment is considered unlikely, these ions were assigned to secondary reactions involving two methanol molecules and were accordingly portioned to the primary products with $\Delta m=+30$ and $+32 .{ }^{d}$ Already at low pressures of $0.5 \times 10^{-4}$ mbar, the IMR of $\mathrm{V}_{3} \mathrm{O}_{5}{ }^{+}$with $\mathrm{CH}_{3} \mathrm{OH}$ leads to secondary reaction products such as $\mathrm{V}_{3} \mathrm{O}_{5}\left(\mathrm{CH}_{3} \mathrm{OH}\right)\left(\mathrm{OCH}_{3}\right)^{+}$and $\mathrm{V}_{3} \mathrm{O}_{4}\left(\mathrm{OCH}_{3}\right)_{2}\left(\mathrm{OCH}_{3}\right)^{+}$; $\mathrm{BRs}$ of these processes were added to that for the association complex.

SCHEME 1: Primary Product Channels for the Dehydrogenation of Methanol by $\mathrm{V}_{m} \mathrm{O}_{n}{ }^{+}$Concomitant with the Release of Formaldehyde and Water (ODH1), Formaldehyde Only (ODH2), Water Only (ODH3), or Molecular Hydrogen (DH)

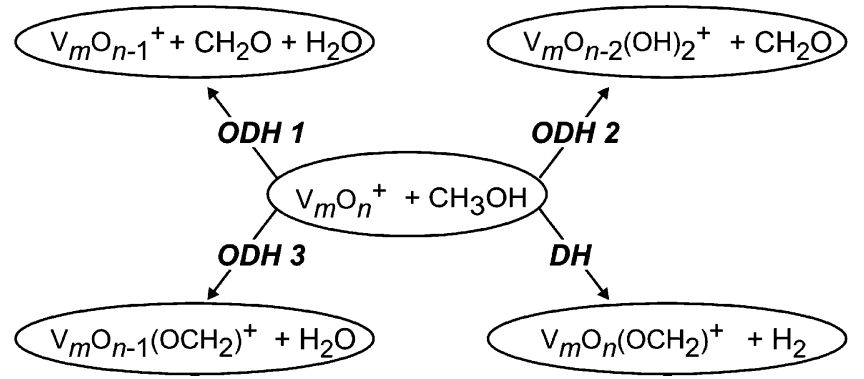

(iii) Mostly for the low-valent vanadium oxides, desoxygenation of methanol concomitant with liberation of methane also occurred $(\Delta m=+16)$, as revealed by labeling experiments with $\mathrm{CD}_{3} \mathrm{OD}$.

(iv) Finally, formal association of methanol with the cluster occurred $(\Delta m=+32)$ and was attributed to the formation of adduct complexes of the type $\mathrm{V}_{m} \mathrm{O}_{n}\left(\mathrm{CH}_{3} \mathrm{OH}\right)^{+}$. Note, however, that the experimental setup does not allow for a further structural characterization of the reaction products formed. Specifically, we cannot distinguish between mere adducts $\mathrm{V}_{m} \mathrm{O}_{n}\left(\mathrm{CH}_{3} \mathrm{OH}\right)^{+}$ and products that might contain newly formed covalent bonds, e.g., $\mathrm{V}_{m} \mathrm{O}_{n-1}(\mathrm{OH})\left(\mathrm{OCH}_{3}\right)^{+}$. In the comparative analysis of the data presented further below, however, $\Delta m=+32$ is considered not as a bond-activation process, but only as simple association.

The various primary IMRs are summarized in Scheme 2, which also includes some secondary reactions, such as the formation of dimethoxo cluster cations of the type $\mathrm{V}_{m} \mathrm{O}_{n-1}\left(\mathrm{OCH}_{3}\right)_{2}{ }^{+}$. For example, the $\mathrm{V}_{m} \mathrm{O}_{n-1}{ }^{+}$products generated upon oxygenatom transfer (ODH1) undergo secondary reactions with methanol to repeat the given reaction pattern and produce the dehydrogenation products $\mathrm{V}_{m} \mathrm{O}_{n-3}(\mathrm{OH})_{2}{ }^{+}$, as well as the adducts $\mathrm{V}_{m} \mathrm{O}_{n-1}\left(\mathrm{CH}_{3} \mathrm{OH}\right)^{+}$. In another subsequent process, $\mathrm{V}_{m} \mathrm{O}_{n-2}\left(\mathrm{OCH}_{3}\right)_{2}{ }^{+}$ is also formed. Further, the $\mathrm{V}_{m} \mathrm{O}_{n-2}(\mathrm{OH})_{2}{ }^{+}$product ions generated upon uptake of two hydrogen atoms undergo second- ary reactions with methanol in which one or both hydroxo groups are replaced by methoxo groups to generate $\mathrm{V}_{m} \mathrm{O}_{n-2}(\mathrm{OH})$ $\left(\mathrm{OCH}_{3}\right)^{+}$or $\mathrm{V}_{m} \mathrm{O}_{n-2}\left(\mathrm{OCH}_{3}\right)_{2}{ }^{+}$, respectively. Some of these secondary reaction products exhibit mass interferences with the primary reaction products of $\mathrm{V}_{m} \mathrm{O}_{n}^{+}$, which renders the quantitative analysis of the data somewhat less accurate but does not affect the general conclusions drawn.

In more detail, hydrogen abstraction from the alcohol results either in the addition of one hydrogen atom to the cluster to generate $\mathrm{V}_{m} \mathrm{O}_{n-1}(\mathrm{OH})^{+}$concomitant with loss of a neutral $\left[\mathrm{CH}_{3} \mathrm{O}\right]^{\bullet}$ species or in the formation of $\mathrm{V}_{m} \mathrm{O}_{n}\left(\mathrm{OCH}_{3}\right)^{+}$accompanied by the expulsion of a hydrogen atom. Hydrogenatom abstraction from methanol to afford $\mathrm{V}_{m} \mathrm{O}_{n-1}(\mathrm{OH})^{+}$occurs almost exclusively for the high-valent tetranuclear oxide cluster $\mathrm{V}_{4} \mathrm{O}_{10}{ }^{+}$. In contrast, generation of $\mathrm{V}_{m} \mathrm{O}_{n}\left(\mathrm{OCH}_{3}\right)^{+}$is preferred in reactions of $\mathrm{CH}_{3} \mathrm{OH}$ with the smaller clusters having lower formal valences, especially with the dinuclear cluster cations (Table 1). Formal $\mathrm{CH}_{3} \mathrm{O}$ abstraction is most likely due to the lower number of electronegative oxo ligands and thus the increased affinities for oxygen-containing ligands of these clusters. Further, several $\mathrm{V}_{m} \mathrm{O}_{n}{ }^{+}$ions show an increase by 16 mass units, which is assigned to addition of an oxygen atom concomitant with liberation of neutral methane. Transfer of a methyl radical $(\Delta m=+15)$ to the clusters occurs only for $\mathrm{V}_{4} \mathrm{O}_{10}{ }^{+}$, whereas addition of the hydroxy group $(\Delta m=+17)$ is preferred for low-valent and smaller clusters, consistent with the larger oxygen affinities of the low-valent clusters.

As mentioned in the Introduction, we focus on the conversion of methanol to formaldehyde. Irrespective of the detailed mechanisms, this process can occur via four different routes (Scheme 1): (i) loss of an oxygen atom from the cluster to form $\mathrm{V}_{m} \mathrm{O}_{n-1}{ }^{+}$with liberation of both neutral water and formaldehyde (ODH1), (ii) transfer of two hydrogen atoms to the cluster concomitant with formation of formaldehyde as a free molecule (ODH2), (iii) formation of formaldehyde as a ligand with water being eliminated as a neutral molecule (ODH3), and (iv) generation of formaldehyde as a ligand bound to the cluster concomitant with loss of $\mathrm{H}_{2}(\mathrm{DH})$. ODH1 is operative for the high-valent tri- and tetranuclear clusters $\mathrm{V}_{3} \mathrm{O}_{6}{ }^{+}, \mathrm{V}_{3} \mathrm{O}_{7}{ }^{+}, \mathrm{V}_{4} \mathrm{O}_{8}{ }^{+}$, $\mathrm{V}_{4} \mathrm{O}_{9}{ }^{+}$, and $\mathrm{V}_{4} \mathrm{O}_{10}{ }^{+}$(Table 1). As exploratory collision-induced 
SCHEME 2: Primary and Secondary Reactions of $\mathrm{V}_{m} \mathrm{O}_{n}{ }^{+}$with Methanol $^{a-c}$



${ }^{a}$ For further details, see Table $1 .{ }^{b}$ Isobaric product ions of primary and secondary reactions are connected by dashed lines. ${ }^{c}$ For the classification of the observed reaction in terms of modes $\mathrm{i}-\mathrm{iv}$, see text.

dissociation (CID) experiments with argon, which has a mass similar to that of methanol, indicated no loss of atomic oxygen from these cluster ions, the occurrence of a net oxygen-atom transfer to the substrate methanol is further substantiated. ${ }^{19}$ Although the nature of the neutral products of ODH1 cannot be probed in the quadrupole setup used, ${ }^{23}$ thermochemical data ${ }^{22}$ favor the formation of $\mathrm{CH}_{2} \mathrm{O}$ and $\mathrm{H}_{2} \mathrm{O}$ rather than any other molecular form of $\mathrm{CH}_{4} \mathrm{O}_{2}$.

Before we address the trends with respect to both dehydrogenation and oxidative dehydrogenation of methanol in more detail, let us briefly discuss some additional information gained from labeling experiments. In the reactions with unlabeled methanol, the mass difference $\Delta m=+16$ can correspond to the expulsion of a $\mathrm{CH}_{4}$ molecule or to the formation of the secondary products $\mathrm{V}_{m} \mathrm{O}_{n-1}\left(\mathrm{CH}_{3} \mathrm{OH}\right)^{+}$and $\mathrm{V}_{m} \mathrm{O}_{n-2}(\mathrm{OH})\left(\mathrm{OCH}_{3}\right)^{+}$ generated in reactions of methanol with the primary ionic products $\mathrm{V}_{m} \mathrm{O}_{n-1}{ }^{+}$and $\mathrm{V}_{m} \mathrm{O}_{n-2}(\mathrm{OH})_{2}{ }^{+}$, respectively (Scheme 2 ). Whereas the ionic product $\mathrm{V}_{m} \mathrm{O}_{n+1}{ }^{+}$can be distinguished in mass from the isobaric secondary products by labeling experiments using $\mathrm{CD}_{3} \mathrm{OD},{ }^{13} \mathrm{CH}_{3} \mathrm{OH}$, and $\mathrm{CH}_{3} \mathrm{OD}$, the distinction of the isomeric secondary products, $\mathrm{V}_{m} \mathrm{O}_{n-1}\left(\mathrm{CH}_{3} \mathrm{OH}\right)^{+}$and $\mathrm{V}_{m} \mathrm{O}_{n-2}(\mathrm{OH})\left(\mathrm{OCH}_{3}\right)^{+}$, cannot be achieved through labeling experiments; consequently, the BRs are proportionally distributed to both primary reaction products $\mathrm{V}_{m} \mathrm{O}_{n-1}{ }^{+}$and $\mathrm{V}_{m} \mathrm{O}_{n-2}(\mathrm{OH})_{2}{ }^{+}$ (Table 1). Further, the $\mathrm{H}$-atom abstraction from methanol as well as the transfer of a $\left[\mathrm{CH}_{3} \mathrm{O}\right]$ unit might involve $\mathrm{C}-\mathrm{H}$ and/ or $\mathrm{O}-\mathrm{H}$ bond cleavage. Labeling experiments with $\mathrm{CH}_{3} \mathrm{OD}$ reveal transfers of both hydrogen and deuterium to the tetranuclear oxide cluster $\mathrm{V}_{4} \mathrm{O}_{10}+$ in a ratio of about $3: 1$. These findings are in good agreement with the fact that $\mathrm{V}_{4} \mathrm{O}_{10}{ }^{+}$can be described as an oxygen-centered radical, which is capable of abstracting an $\mathrm{H}$-atom even from methane. ${ }^{24,25}$ Accordingly, it is not at all surprising that $\mathrm{V}_{4} \mathrm{O}_{10}{ }^{+}$can also abstract a hydrogen atom from methanol, regardless of whether the weaker $\mathrm{C}-\mathrm{H}$ or the stronger $\mathrm{O}-\mathrm{H}$ bond is to be cleaved; we note, however, that $\mathrm{H} / \mathrm{D}$ equilibration between the $\mathrm{C}-\mathrm{H}$ and $\mathrm{O}-\mathrm{D}$ bonds can also account for the $3: 1$ ratio of $\mathrm{H}$ and $\mathrm{D}$ transfers observed experimentally. With respect to $\Delta m=+31$, labeling experiments with $\mathrm{CH}_{3} \mathrm{OD}$ suggest the generation of $\mathrm{V}_{m} \mathrm{O}_{n}\left(\mathrm{CH}_{2} \mathrm{OD}\right)^{+}$ via expulsion of a hydrogen atom from the methyl group. Upon increasing the methanol pressure to $1 \times 10^{-3}$ mbar, the product $\mathrm{V}_{m} \mathrm{O}_{n}\left(\mathrm{OCH}_{3}\right)^{+}$predominates, most likely as a result of substitution of the $\mathrm{CH}_{2} \mathrm{OD}$ ligand by a methoxo group in secondary collisions. Concerning ODH2, experiments with $\mathrm{CH}_{3} \mathrm{OD}$ reveal an exclusive transfer of HD and thus confirm the occurrence of a 1,2-elimination for all vanadium oxide clusters examined. An exception is $\mathrm{V}_{4} \mathrm{O}_{10}{ }^{+}$, for which the mass differences $\Delta m=+1$, +2 , and +3 were observed in the reaction with $\mathrm{CH}_{3} \mathrm{OD}$. The former and the latter certainly can be assigned to the addition of one hydrogen atom and to a 1,2-elimination of $\mathrm{HD}$ from $\mathrm{CH}_{3}-$ $\mathrm{OD}$, respectively. However, the increase by 2 mass units can be assigned either to 1,2-elimination of $\mathrm{H}_{2}$ from an impurity of unlabeled methanol present in the reaction cell, to deuterium abstraction from $\mathrm{CH}_{3} \mathrm{OD}$, to an equilibration of the $\mathrm{H}$ and $\mathrm{D}$ atoms, or even to a 1,1-elimination from the methoxy group. ${ }^{26}$ Given that H/D equilibration has previously been observed in the dehydrogenation of isomeric butenes by $\mathrm{V}_{4} \mathrm{O}_{10}{ }^{+}$ions, ${ }^{13}$ its occurrence for methanol is not entirely unexpected.

As an example, let us refer to the reaction of the cluster ion $\mathrm{V}_{2} \mathrm{O}_{4}{ }^{+}$with methanol, which was previously examined by Justes et al. ${ }^{6}$ Figure 1 shows the ionic products observed when massselected $\mathrm{V}_{2} \mathrm{O}_{4}{ }^{+}(\mathrm{m} / \mathrm{z}=166)$ is allowed to interact with methanol. The most abundant product corresponds to the $\mathrm{V}_{2} \mathrm{O}_{2}$ $(\mathrm{OH})_{2}{ }^{+}$ion $(\mathrm{m} / \mathrm{z}=168)$ resulting from the uptake of dihydrogen by the cluster concomitant with the release of formaldehyde $(\mathrm{ODH} 2)$. For the product ion with $\mathrm{m} / \mathrm{z}=182$, two assignments are conceivable. One corresponds to $\mathrm{V}_{2} \mathrm{O}_{5}{ }^{+}$, formed via oxygenatom abstraction from methanol, and the other to the isobaric species $\mathrm{V}_{2} \mathrm{O}_{2}(\mathrm{OH})\left(\mathrm{OCH}_{3}\right)^{+}$generated in a secondary reaction of $\mathrm{V}_{2} \mathrm{O}_{2}(\mathrm{OH})_{2}{ }^{+}$with methanol; judging from the reactions with $\mathrm{CD}_{3} \mathrm{OD}$, the two ions are formed in a ratio of about 1:2. Likewise, the ionic product at $\mathrm{m} / \mathrm{z}=196$ can be assigned to a 1:2 mixture of $\mathrm{V}_{2} \mathrm{O}_{4}\left(\mathrm{OCH}_{2}\right)^{+}$resulting from dehydrogenation of methanol $(\mathrm{DH})$ and $\mathrm{V}_{2} \mathrm{O}_{2}\left(\mathrm{OCH}_{3}\right)_{2}{ }^{+}$generated upon collision 




Figure 1. Reaction of mass-selected $\mathrm{V}_{2} \mathrm{O}_{4}{ }^{+}$with methanol $(p=1 \times$ $10^{-4}$ mbar) at a collision energy adjusted to nominally $0 \mathrm{eV}$. Signals marked with an asterisk are due to impurities; see Experimental Methods for further details.

of the primary product $\mathrm{V}_{2} \mathrm{O}_{2}(\mathrm{OH})_{2}{ }^{+}$with another methanol molecule. Finally, the weak signal at $\mathrm{m} / \mathrm{z}=198$ corresponds to the formal adduct $\mathrm{V}_{2} \mathrm{O}_{4}\left(\mathrm{CH}_{3} \mathrm{OH}\right)^{+}$. We note that the abstraction of a methyl radical from the neutral reagent reported by Justes et al. ${ }^{6}$ was not observed to take place to a significant extent under our experimental conditions (absence of a signal at $\mathrm{m} / \mathrm{z}$ $=181$ in Figure 1). In contrast, uptake of an oxygen atom occurs to produce $\mathrm{V}_{2} \mathrm{O}_{5}{ }^{+}$, and in the dehydrogenation of methanol, formaldehyde is retained as a ligand to $\mathrm{V}_{2} \mathrm{O}_{4}{ }^{+}(\mathrm{m} / \mathrm{z}=196)$; signals indicative of these two processes were not reported in the experiments of Justes et al. ${ }^{6}$

As a representative example for isobaric interferences due to primary and secondary ionic reaction products, the ionmolecule processes of the cluster cation $\mathrm{V}_{3} \mathrm{O}_{7}{ }^{+}$with methanol are shown in Figure 2. The five primary reaction products correspond to $\mathrm{V}_{3} \mathrm{O}_{6}{ }^{+}, \mathrm{V}_{3} \mathrm{O}_{5}(\mathrm{OH})_{2}{ }^{+}, \mathrm{V}_{3} \mathrm{O}_{6}\left(\mathrm{OCH}_{2}\right)^{+}, \mathrm{V}_{3} \mathrm{O}_{8}{ }^{+}$, and $\mathrm{V}_{3} \mathrm{O}_{7}\left(\mathrm{CH}_{3} \mathrm{OH}\right)^{+}$(highlighted black in Figure 2a). The product ion at $\mathrm{m} / \mathrm{z}=311$ corresponds to the dehydration of two methanol molecules to produce neutral water and $\mathrm{V}_{3} \mathrm{O}_{6}\left(\mathrm{OCH}_{3}\right)_{2}{ }^{+}$(Figure 2a). As supported by labeling experiments, the signals at $\mathrm{m} / \mathrm{z}$ $=281$ and 295 can also be assigned to secondary reactions of the ODH2 product with methanol to form the substitution products $\mathrm{V}_{3} \mathrm{O}_{5}(\mathrm{OH})\left(\mathrm{OCH}_{3}\right)^{+}$and $\mathrm{V}_{3} \mathrm{O}_{5}\left(\mathrm{OCH}_{3}\right)_{2}{ }^{+}$upon loss of water (Figure $2 \mathrm{~b}$ ) and/or secondary collision reactions of the ODH1 product with methanol to generate the association complex $\mathrm{V}_{3} \mathrm{O}_{6}\left(\mathrm{CH}_{3} \mathrm{OH}\right)^{+}$and the condensation product $\mathrm{V}_{3} \mathrm{O}_{5^{-}}$ $\left(\mathrm{OCH}_{3}\right)_{2}{ }^{+}$(Figure 2c). As mentioned above, the signals of the secondary reaction products cannot be further distinguished by labeling experiments; in the evaluation of the data, the BRs are accordingly distributed proportionally to the two primary reaction products.

A more general survey of the ion-molecule reactions reported here reveals that oxidative dehydrogenation of methanol is preferred for the high-valent cluster cations, whereas the lowvalent clusters show little or no reactivity with respect to $\mathrm{H}_{2}$ uptake (Table 1). This is clearly indicated upon inspection of Figure 3 in which the efficiencies of these channels are plotted as a function of the formal valence of vanadium in the cluster cations.

Obviously, the higher the formal valence of the metal in the cluster ions, the greater the $\mathrm{ODH}$ activity (Figure $3 \mathrm{a}-\mathrm{c}$ ). In contrast, upon inspection of Figure 3d, it becomes obvious that, among the low-valent cluster cations, almost only $\mathrm{VO}^{+}$shows activity with respect to $\mathrm{DH}$, whereas most of the remaining vanadium oxide cations appear to be unreactive with respect to


Figure 2. (a) Primary IMR of $\mathrm{V}_{3} \mathrm{O}_{7}^{+}$, (b) secondary IMR of $\mathrm{V}_{3} \mathrm{O}_{5}^{-}$ $(\mathrm{OH})_{2}{ }^{+}$, and (c) secondary IMR of $\mathrm{V}_{3} \mathrm{O}_{6}{ }^{+}$with methanol. $p$ (methanol) $=1 \times 10^{-4}$ mbar; collision energy adjusted to nominally $0 \mathrm{eV}$. The relevant signals are highlighted in black; see text. The corresponding reactant ions are marked with an asterisk.

dehydrogenation, with $\mathrm{V}_{2} \mathrm{O}_{4}{ }^{+}$being between these extremes. Furthermore, the dependence of the ODH activity on the formal valence of vanadium for ODH3 is similar to those for ODH1 and $\mathrm{ODH} 2$ (Figure 3c). Hence, the higher the formal valence, the greater the tendency to eliminate neutral water. Last but not least, the activity for ODH1 is displayed in Figure 3a. Obviously, the formal transfer of an $\mathrm{O}$ atom to methanol also increases with the formal valence of the vanadium. ${ }^{19}$ These findings can be explained as follows: High-valent metal oxo cations, such as $\mathrm{V}_{4} \mathrm{O}_{10}{ }^{+}$, exhibit a higher $\mathrm{H}$-atom affinity because of the larger number of electronegative oxo ligands and, thus, favor ODH with respect to transfer of two hydrogen atoms to the oxo ligands, followed by liberation of $\mathrm{H}_{2} \mathrm{O}(\mathrm{ODH} 3)$, elimination of $\mathrm{CH}_{2} \mathrm{O}(\mathrm{ODH} 2)$, or elimination of $\mathrm{H}_{2} \mathrm{O}$ and $\mathrm{CH}_{2} \mathrm{O}$ together (ODH1). In contrast, the low-valent ions have occupied $\mathrm{d}$ orbitals that are suitable for interaction with the empty $\pi^{*}$ orbital of the carbonyl group in formaldehyde, and preference for the DH route is consequently observed.

In addition to the valence of the metal in the cluster ions, consideration of the respective recombination energies (REs) ${ }^{27}$ of the cluster cations is indicated because the oxidative dehydrogenation of methanol via ODH2 involves uptake of two protons and two electrons by the cluster. Consequently, a comparison of the recombination energies of the vanadium oxide 

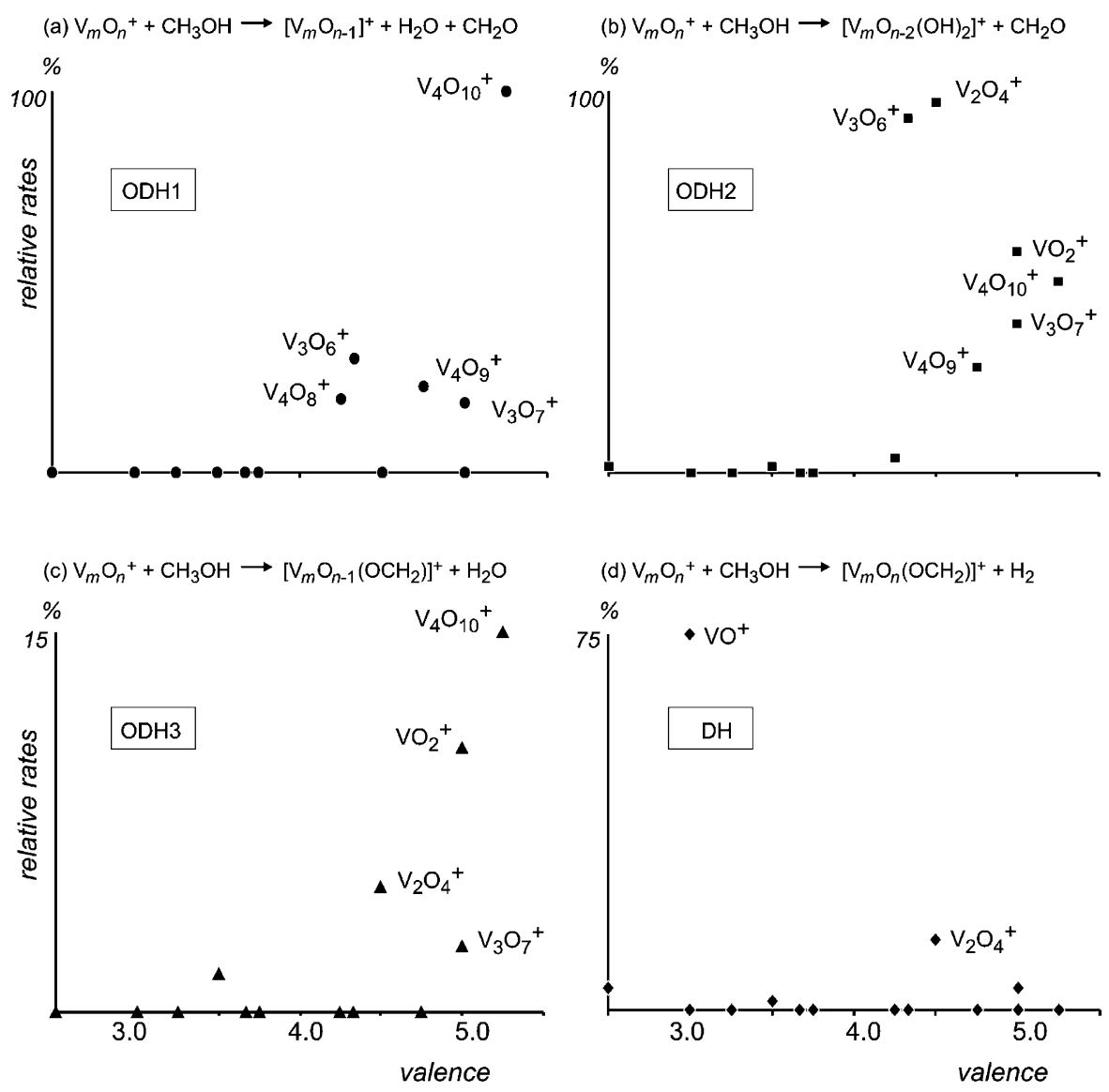

Figure 3. Relative rates of the reactions (a) ODH1, (b) ODH2, (c) ODH3, and (d) DH as a function of the formal valence of vanadium in the $\mathrm{V}_{m} \mathrm{O}_{n}{ }^{+}$clusters.

TABLE 2: Ratios $X\left[X=\mathrm{V}_{m} \mathrm{O}_{n}\left(\mathrm{CH}_{3} \mathrm{OH}\right)^{+} / \mathrm{V}_{m} \mathrm{O}_{n-1}\left(\mathrm{OCH}_{3}\right)_{2}{ }^{+}\right]$ in the IMR of $\mathrm{V}_{m} \mathrm{O}_{n}{ }^{+}$Cations with Methanol

\begin{tabular}{lrll}
\hline $\mathrm{V}_{m} \mathrm{O}_{n}{ }^{+}$ & $X$ & $\mathrm{~V}_{m} \mathrm{O}_{n}{ }^{+}$ & $X$ \\
\hline $\mathrm{VO}^{+}$ & 11 & $\mathrm{~V}_{3} \mathrm{O}_{6}{ }^{+}$ & 2 \\
$\mathrm{VO}_{2}{ }^{+}$ & 40 & $\mathrm{~V}_{3} \mathrm{O}_{7}^{+}$ & 2 \\
$\mathrm{~V}_{2} \mathrm{O}_{2}{ }^{+}$ & 5 & $\mathrm{~V}_{4} \mathrm{O}_{6}{ }^{+}$ & 2 \\
$\mathrm{~V}_{2} \mathrm{O}_{3}^{+}$ & 2 & $\mathrm{~V}_{4} \mathrm{O}_{7}^{+}$ & 1 \\
$\mathrm{~V}_{2} \mathrm{O}_{4}^{+}$ & 6 & $\mathrm{~V}_{4} \mathrm{O}_{8}^{+}$ & 1 \\
$\mathrm{~V}_{3} \mathrm{O}_{4}^{+}$ & 1 & $\mathrm{~V}_{4} \mathrm{O}_{9}^{+}$ & 1 \\
$\mathrm{~V}_{3} \mathrm{O}_{5}^{+}$ & 2 & $\mathrm{~V}_{4} \mathrm{O}_{10}^{+}$ & 4
\end{tabular}

cluster cations might also shed light on the observed trends. Qualitatively, an apparent threshold of about $\mathrm{RE}=8 \mathrm{eV}$ for the occurrence of ODH2 is implied; specifically, $\mathrm{V}_{2} \mathrm{O}_{4}{ }^{+}(\mathrm{RE}=$ $8.17 \mathrm{eV}), \mathrm{V}_{2} \mathrm{O}_{5}{ }^{+}(\mathrm{RE}=9.8 \mathrm{eV}), \mathrm{V}_{2} \mathrm{O}_{6}{ }^{+}(\mathrm{RE}=8.4 \mathrm{eV}), \mathrm{V}_{3} \mathrm{O}_{6}{ }^{+}$ $(\mathrm{RE}=8.26 \mathrm{eV}), \mathrm{V}_{3} \mathrm{O}_{7}{ }^{+}(\mathrm{RE}=8.96 \mathrm{eV}), \mathrm{V}_{3} \mathrm{O}_{8}{ }^{+}(\mathrm{RE}=10.6$ $\mathrm{eV})$, and $\mathrm{V}_{4} \mathrm{O}_{10}{ }^{+}(\mathrm{RE}=11.2 \mathrm{eV})$ lead to the release of formaldehyde, whereas $\mathrm{VO}^{+}(\mathrm{RE}=7.2 \mathrm{eV})$ and $\mathrm{V}_{2} \mathrm{O}_{3}{ }^{+}(\mathrm{RE}=$ $6.55 \mathrm{eV}$ ) have recombination energies too low to bring about the oxidative dehydrogenation of methanol and are thus (more or less) unreactive with respect to ODH2.6,22,28,29 The recombination energies of the clusters can hence be regarded as a qualitative measure of the clusters' ability to oxidize the neutral substrate: ${ }^{30} \mathrm{~V}_{m} \mathrm{O}_{n}{ }^{+}$clusters with low oxygen content bear lowvalent vanadium centers with low REs and high oxygen affinities, whereas oxygen-rich clusters have high REs and are thus more powerful oxidants.

The association products $\mathrm{V}_{m} \mathrm{O}_{n}\left(\mathrm{CH}_{3} \mathrm{OH}\right)^{+}$undergo several subsequent reactions with methanol to, among others, form dimethoxo vanadium oxide clusters of the general type $\mathrm{V}_{m} \mathrm{O}_{n-1}\left(\mathrm{OCH}_{3}\right)_{2}{ }^{+}$concomitant with elimination of neutral water. Labeling studies with $\mathrm{CH}_{3}{ }^{18} \mathrm{OH}$ show that both light and heavy water molecules are liberated; thus, transfer of two hydrogen atoms from the hydroxy groups of two methanol molecules to the cluster concomitant with loss of $\mathrm{H}_{2} \mathrm{O}$ is substantiated in addition to condensation of two methanol molecules to eliminate $\mathrm{H}_{2}{ }^{18} \mathrm{O}$ in a ratio of about $3: 1$. Interestingly, the ratio of the BRs of the association complex $\mathrm{V}_{m} \mathrm{O}_{n}\left(\mathrm{CH}_{3} \mathrm{OH}\right)^{+}$and the dimethoxo product $\mathrm{V}_{m} \mathrm{O}_{n-1}\left(\mathrm{OCH}_{3}\right)_{2}{ }^{+}$depends on the size of the metal oxide cluster. This conclusion becomes obvious upon inspection of Table 2 in which the ratios for $\mathrm{V}_{m} \mathrm{O}_{n}\left(\mathrm{CH}_{3} \mathrm{OH}\right)^{+}$and $\mathrm{V}_{m} \mathrm{O}_{n-1}\left(\mathrm{OCH}_{3}\right)_{2}{ }^{+}$ clearly decrease with increasing number of vanadium atoms in the metal oxide clusters. In contrast, for a given number of vanadium atoms in the cluster, simple association is favored relative to the condensation of two methanol ligands with increasing number of electronegative oxo ligands. The explanation for this phenomenon is rather obvious: The larger the cluster is, the more likely collisions with a second methanol molecule become because the lifetimes of the encounter complexes increase with size such that the energy gained upon coordination of two methanol molecules can be redistributed more efficiently within the cluster, thus rendering redissociation into the reactants less likely.

The reactivity of vanadium oxide cluster cations toward methanol has already been studied by Justes et al. ${ }^{6}$ using a guided-ion-beam mass spectrometer coupled to a laser vaporization ion source. A comparison with the present experiment, in which ESI was used for the generation of the cluster ions, reveals some major differences, which are most likely associated with the mode of ion generation because the experimental conditions in the reactivity studies are quite comparable. For instance the former work reports products due to additions of $\mathrm{H}_{2}, \mathrm{CH}_{3}, \mathrm{CH}_{3}$ $\mathrm{OH}$, and $\mathrm{C}_{2} \mathrm{H}_{6} \mathrm{O}$ to the mass-selected cluster ions. Our experiments confirm molecular association and formation of the 
SCHEME 3: Primary, Secondary, and Tertiary Reactions of $\mathrm{V}_{m} \mathrm{O}_{n-1}(\mathrm{OD})^{+}$with Methanol ${ }^{a}$ primary reactions secondary reactions

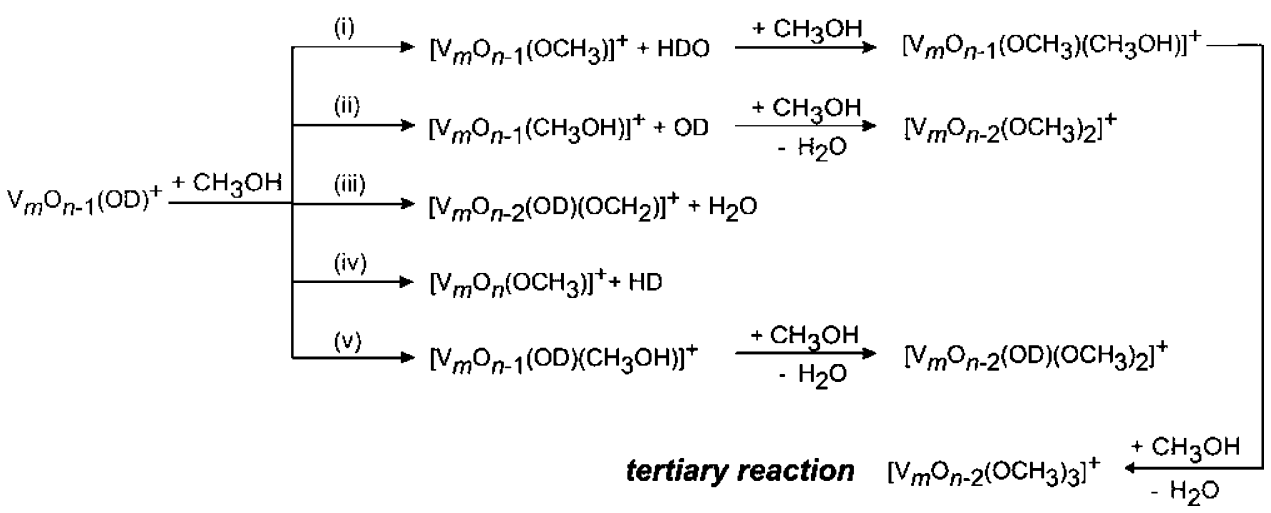

${ }^{a}$ For the classification of the observed reaction in terms of modes $i-v$, see text.

TABLE 3: Mass Differences $(\Delta m$ in amu), Branching Ratios (BRs with $\left.\sum \mathrm{BR}_{i}=100\right)$, Relative Rate Constants $\left(\boldsymbol{k}_{\text {rel }}\right)$, and Formal Valence (fv) Values of the Clusters in the Ion-Molecule Reactions of $\mathrm{V}_{m} \mathrm{O}_{n-1}(\mathrm{OD})^{+}$Cations with Methanol $^{a}$

\begin{tabular}{lcccrcc}
\hline & & & \multicolumn{5}{c}{$\Delta m$} \\
\cline { 5 - 8 } $\mathrm{V}_{m} \mathrm{O}_{n-1}(\mathrm{OD})^{+}$ & $k_{\text {rel }}{ }^{b}$ & $\mathrm{fv}$ & +13 & +14 & +29 & $+32^{c}$ \\
\hline $\mathrm{V}(\mathrm{OD})^{+d}$ & 18 & 2.00 & 75 & & 23 & \\
$\mathrm{VO}(\mathrm{OD})^{+}$ & 29 & 3.00 & 90 & 10 & & \\
$\mathrm{~V}_{2} \mathrm{O}(\mathrm{OD})^{+e, f}$ & 45 & 2.00 & 45 & 15 & 20 & 20 \\
$\mathrm{~V}_{2} \mathrm{O}_{2}(\mathrm{OD})^{+e . f}$ & 24 & 3.00 & 60 & 10 & 5 & 25 \\
$\mathrm{~V}_{2} \mathrm{O}_{3}(\mathrm{OD})^{+}$ & 50 & 4.00 & 75 & 15 & & 10 \\
$\mathrm{~V}_{3} \mathrm{O}_{3}(\mathrm{OD})^{+}$ & 41 & 2.67 & 50 & 10 & 10 & 30 \\
$\mathrm{~V}_{3} \mathrm{O}_{4}(\mathrm{OD})^{+f}$ & 48 & 3.33 & 75 & 5 & $-\mathrm{f}$ & 20 \\
$\mathrm{~V}_{3} \mathrm{O}_{5}(\mathrm{OD})^{+}$ & 60 & 4.00 & 41 & 6 & 2 & 51 \\
$\mathrm{~V}_{3} \mathrm{O}_{6}(\mathrm{OD})^{+f}$ & 58 & 4.67 & 35 & 20 & $-\mathrm{f}$ & 45 \\
$\mathrm{~V}_{4} \mathrm{O}_{6}(\mathrm{OD})^{+f}$ & 92 & 3.50 & 80 & 10 & $-\mathrm{f}$ & 15 \\
$\mathrm{~V}_{4} \mathrm{O}_{7}(\mathrm{OD})^{+g}$ & 78 & 4.00 & 77 & 5 & 2 & 16 \\
$\mathrm{~V}_{4} \mathrm{O}_{8}(\mathrm{OD})^{+e}$ & 84 & 4.50 & 41 & 5 & & 54 \\
$\mathrm{~V}_{4} \mathrm{O}_{9}(\mathrm{OD})^{+e . f}$ & 75 & 5.00 & 15 & 5 & $-\mathrm{f}$ & 80 \\
& & & & & &
\end{tabular}

${ }^{a}$ Product ions with $\mathrm{BR} \approx 1 \%$ are omitted. ${ }^{b} k_{\text {rel }}$ values were normalized to the highest $k_{\text {rel }}$ obtained for $\mathrm{V}_{m} \mathrm{O}_{n}{ }^{+}$; see Table 1, according to which $k_{\text {rel }}=100$ corresponds to $k_{\text {abs }}=(5.0 \pm 1.5) \times 10^{-10} \mathrm{~cm}^{3}$ molecules ${ }^{-1} \mathrm{~s}^{-1}$. ${ }^{c}$ BRs for secondary reactions, such as condensation of two methanol molecules to form the dimethoxo clusters $\mathrm{V}_{m} \mathrm{O}_{n-1}\left(\mathrm{OCH}_{3}\right)_{2}{ }^{+}$, were added to the BRs of the association complex $(\Delta m=+32) .{ }^{d} \mathrm{IMR}$ of $\mathrm{V}(\mathrm{OD})^{+}$with methanol also resulted in desoxygenation of methanol $(\mathrm{BR}=1)$ and abstraction of a hydroxyl group $(\mathrm{BR}=1) .{ }^{e}$ Generated oxovanadium hydroxide cluster cations overlap with $\mathrm{V}_{m} \mathrm{O}_{n-2}\left(\mathrm{OCD}_{3}\right)^{+}$, as implied by the observation of a signal with $\Delta m=-3$, indicating the substitution of an $\mathrm{OCD}_{3}$ ligand by $\mathrm{OCH}_{3}$ (see Experimental Methods). ${ }^{f}$ Spectra contained background interference, thus making analyses of BRs of less than $5 \%$ difficult. $\mathrm{BR}=x \leq 5 .{ }^{g}$ For a possible contribution of isobaric $\mathrm{V}_{4} \mathrm{O}_{6}(\mathrm{OD})\left(\mathrm{OCH}_{2}\right)^{+}$to the signal with $\Delta m=$ +14 , see text.

dimethoxo cluster cation $\mathrm{V}_{m} \mathrm{O}_{n-2}\left(\mathrm{OCH}_{3}\right)_{2}{ }^{+}$(equivalent to $\mathrm{V}_{m} \mathrm{O}_{n} \mathrm{C}_{2} \mathrm{H}_{6} \mathrm{O}^{+}$) as well as $\mathrm{ODH} 2$ to produce $\mathrm{V}_{m} \mathrm{O}_{n-2}(\mathrm{OH})_{2}{ }^{+}$; however, abstraction of $\mathrm{CH}_{3}$ was observed only for $\mathrm{V}_{4} \mathrm{O}_{10}{ }^{+}$. Furthermore, one of the fundamental reaction channels in our system corresponds to the desoxygenation of methanol, which was not reported in ref 6 . For the vanadium oxide cluster cations investigated in both studies, Justes et al. ${ }^{6}$ reported uptake of $\mathrm{H}_{2}$ for $\mathrm{VO}_{2}^{+}, \mathrm{V}_{2} \mathrm{O}_{4}{ }^{+}$, and $\mathrm{V}_{3} \mathrm{O}_{7}{ }^{+}$. In addition to these vanadium oxides, our experiments demonstrated attachment of $\mathrm{H}_{2}$ also to the mass-selected ions $\mathrm{V}_{3} \mathrm{O}_{6}{ }^{+}, \mathrm{V}_{4} \mathrm{O}_{9}{ }^{+}$, and $\mathrm{V}_{4} \mathrm{O}_{10}{ }^{+}$(Table 1). Interestingly, association of formaldehyde to the cluster concomitant with liberation of neutral $\mathrm{H}_{2}$ was not observed by Justes et al. ${ }^{6}$ In general, the present experiments found more diverse reaction pathways than the previous investigation. ${ }^{6}$ Possible explanations for the different experimental findings might be found in the different types of cluster-ion sources used, and in this respect, it is conceivable that excited states or isomeric ions were produced with the two different kinds of ion sources. ${ }^{31}$ Alternatively, the two methods of ion generation might lead to gaseous clusters with different internal energy content and hence effective cluster-ion temperatures. ${ }^{32}$ Further experiments are needed to address this problem and to resolve the current discrepancies, and most desirable would be a direct comparison of the gas-phase reactivity of $\mathrm{V}_{m} \mathrm{O}_{n}{ }^{+}$clusters generated using both methods in a single experimental setup combined with adequate ion thermalization. ${ }^{33}$

Oxovanadium Hydroxides. For comparison with the vanadium oxide cluster cations, the IMRs of methanol with cationic hydroxo clusters having the general formula $\mathrm{V}_{m} \mathrm{O}_{n-1}(\mathrm{OD})^{+}$were also considered (Table 3 ). With regard to the oxidative dehydrogenation of methanol, however, neither $\mathrm{H}_{2}$ uptake concomitant with loss of neutral formaldehyde nor loss of an oxygen atom to produce neutral water and formaldehyde nor loss of $\mathrm{H}_{2}$ with attachment of formaldehyde as a ligand take place.

The reactions observed can instead be grouped into five different categories (Scheme 3):

(i) Condensation reactions to form $\mathrm{V}_{m} \mathrm{O}_{n-1}\left(\mathrm{OCH}_{3}\right)^{+}(\Delta m=$ +13 ) concomitant with loss of HDO correspond to the major reaction channel for $\mathrm{V}_{m} \mathrm{O}_{n-1}(\mathrm{OD})^{+}$. Note that the exclusive loss of $\mathrm{HDO}$ observed in the condensation process with $\mathrm{CH}_{3}{ }^{18} \mathrm{OH}$ (Figure 4) can be viewed as further evidence that ESI of $\mathrm{V}_{6} \mathrm{O}_{7}$ $\left(\mathrm{OCH}_{3}\right)_{12}$, dissolved in $\mathrm{CD}_{3} \mathrm{OD}$, leads to the formation of genuine vanadium hydroxide clusters $\mathrm{V}_{m} \mathrm{O}_{n-1}(\mathrm{OD})^{+}$, rather than the corresponding hydrido isomers $\mathrm{DV}_{m} \mathrm{O}_{n}{ }^{+}$, for which dehydrogenation would be expected. ${ }^{34}$

(ii) Association of $\mathrm{CH}_{3} \mathrm{OH}$ combined with the expulsion of an $\mathrm{OD}$ radical leads to the generation of $\mathrm{V}_{m} \mathrm{O}_{n-1}\left(\mathrm{CH}_{3} \mathrm{OH}\right)^{+}$ species $(\Delta m=+14)$.

(iii) The reactions of $\mathrm{V}_{m} \mathrm{O}_{n-1}(\mathrm{OD})^{+}$with methanol also result in the elimination of $\mathrm{H}_{2} \mathrm{O}$ to form $\mathrm{V}_{m} \mathrm{O}_{n-2}(\mathrm{OD})\left(\mathrm{OCH}_{2}\right)^{+}(\Delta m$ $=+14)$. Note that categories ii and iii lead to isobaric product ions, whose distinction is discussed later in the text.

(iv) Elimination of HD affords methoxo clusters of the type $\mathrm{V}_{m} \mathrm{O}_{n}\left(\mathrm{OCH}_{3}\right)^{+}(\Delta m=+29)$.

(v) Finally, molecular association to the formal adduct ions $\mathrm{V}_{m} \mathrm{O}_{n-1}(\mathrm{OD})\left(\mathrm{CH}_{3} \mathrm{OH}\right)^{+}$is observed for all polynuclear $\mathrm{V}_{m} \mathrm{O}_{n-1}(\mathrm{OD})^{+}$ clusters $(\Delta m=+32)$.

As for the vanadium oxide clusters, the oxovanadium hydroxide clusters undergo a sequence of secondary and even tertiary reactions. For example, $\mathrm{V}_{m} \mathrm{O}_{n-1}\left(\mathrm{OCH}_{3}\right)\left(\mathrm{CH}_{3} \mathrm{OH}\right)^{+}$is formed upon association of methanol to the ionic product $\mathrm{V}_{m} \mathrm{O}_{n-1}\left(\mathrm{OCH}_{3}\right)^{+}$, and the product ions $\mathrm{V}_{m} \mathrm{O}_{n-2}\left(\mathrm{OCH}_{3}\right)_{2}{ }^{+}$, 

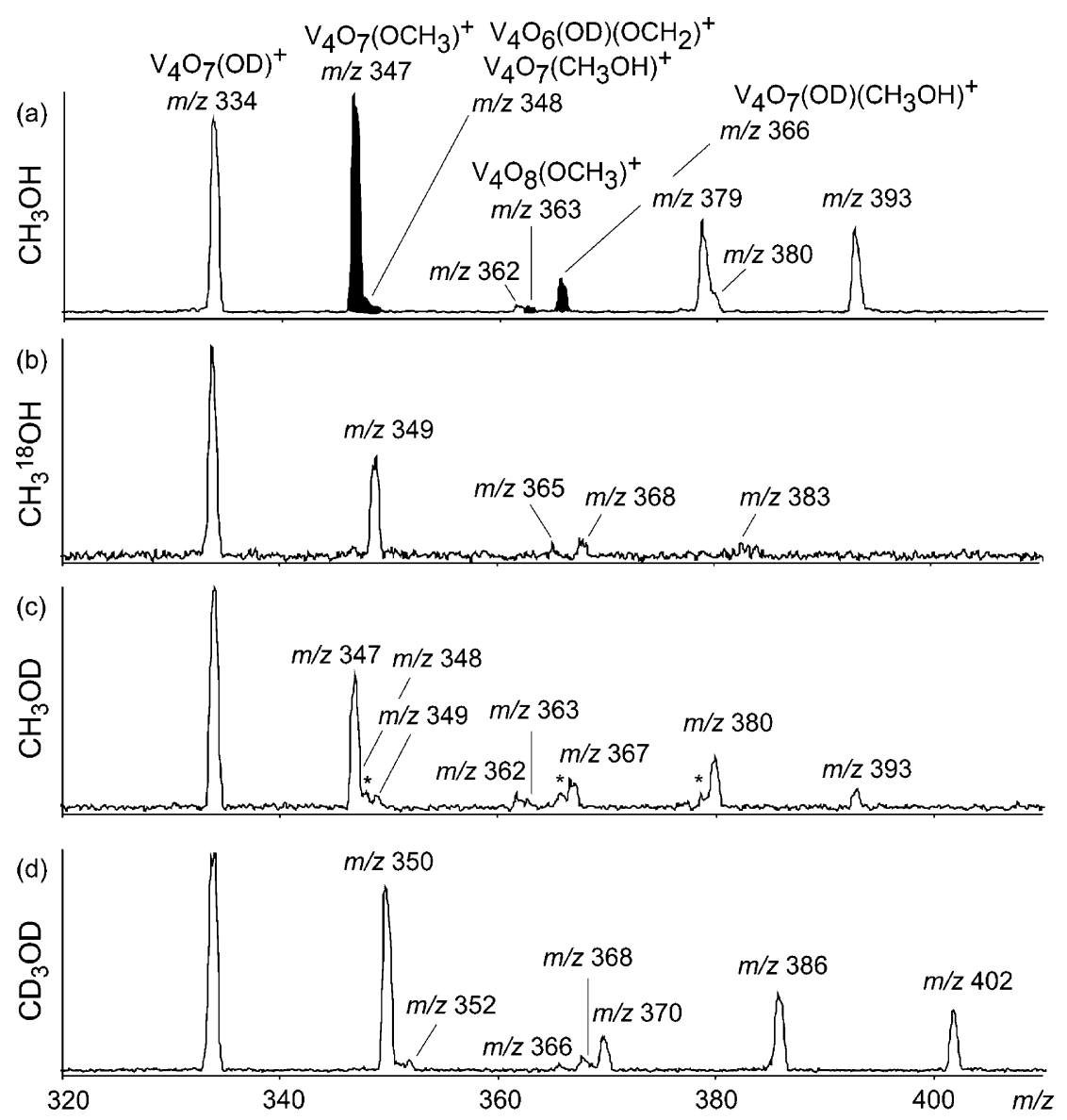

Figure 4. Reaction of mass-selected $\mathrm{V}_{4} \mathrm{O}_{7}(\mathrm{OD})^{+}\left(\mathrm{m} / \mathrm{z}\right.$ 334) with (a) $\mathrm{CH}_{3} \mathrm{OH}$, (b) $\mathrm{CH}_{3}{ }^{18} \mathrm{OH}$, (c) $\mathrm{CH}_{3} \mathrm{OD}$, and (d) $\mathrm{CD}_{3} \mathrm{OD}\left(p=\mathrm{ca} .1 \times 10^{-4} \mathrm{mbar}\right)$ at a collision energy adjusted to nominally $0 \mathrm{eV}$. The signals assigned to the primary IMR of $\mathrm{V}_{4} \mathrm{O}_{7}(\mathrm{OD})^{+}$with $\mathrm{CH}_{3} \mathrm{OH}$ are highlighted in black; see text. Signals marked with an asterisk in Figure $4 \mathrm{c}$ are due to reactions with a $\mathrm{CH}_{3} \mathrm{OH}$ impurity in the $\mathrm{CH}_{3} \mathrm{OD}$ sample.

SCHEME 4: Conceivable Reaction Channels of $\mathrm{V}_{m} \mathrm{O}_{n-1}(\mathrm{OD})^{+}$with Methanol for the Signal at $(\Delta m=+14)^{a}$



${ }^{a}$ Oxygen atom of methanol is highlighted in bold; see text for further details.

$\mathrm{V}_{m} \mathrm{O}_{n-2}(\mathrm{OD})\left(\mathrm{OCH}_{3}\right)_{2}{ }^{+}$, and $\mathrm{V}_{m} \mathrm{O}_{n-2}\left(\mathrm{OCH}_{3}\right)_{3}{ }^{+}$result via elimination of water upon a second and third collision with methanol of the primary reaction products $\mathrm{V}_{m} \mathrm{O}_{n-1}\left(\mathrm{CH}_{3} \mathrm{OH}\right)^{+}$and $\mathrm{V}_{m} \mathrm{O}_{n-1}(\mathrm{OD})\left(\mathrm{CH}_{3} \mathrm{OH}\right)^{+}$and the secondary product $\mathrm{V}_{m} \mathrm{O}_{n-1}\left(\mathrm{OCH}_{3}\right)-$ $\left(\mathrm{CH}_{3} \mathrm{OH}\right)^{+}$, respectively (Scheme 3 ). In Table 3 , these secondary and tertiary product ions are accordingly added to the BRs of the corresponding primary reaction products.

Labeling experiments with $\mathrm{CH}_{3} \mathrm{OD}$ indicate that the signal at $\Delta m=+13$ is formed upon elimination of HDO, with the hydrogen mainly stemming from the hydroxy group in methanol. With regard to the product ion with $\Delta m=+14$, three different channels are conceivable: (i) exchange of the OD group by a methanol molecule, (ii) dehydration following association with methanol, and (iii) oxidative dehydrogenation of methanol (Scheme 4). A distinction of the two latter channels was not possible via labeling experiments, but their abundances are also rather low. Further, the substitution of the OD group in the oxovanadium hydroxide clusters by a methanol molecule to afford $\mathrm{V}_{m} \mathrm{O}_{n-1}\left(\mathrm{CH}_{3} \mathrm{OH}\right)^{+}(\Delta m=+14)$ is confirmed by the reactions with $\mathrm{CH}_{3} \mathrm{OD}$ and $\mathrm{CD}_{3} \mathrm{OD}$.
As an example, Figure 4 shows the ionic products observed when mass-selected $\mathrm{V}_{4} \mathrm{O}_{7}(\mathrm{OD})^{+}(\mathrm{m} / \mathrm{z}=334)$ was allowed to interact with the labeled methanol species $\mathrm{CH}_{3} \mathrm{OH}, \mathrm{CH}_{3}{ }^{18} \mathrm{OH}$, $\mathrm{CH}_{3} \mathrm{OD}$, and $\mathrm{CD}_{3} \mathrm{OD}$. The five primary reaction products for the interaction with unlabeled methanol are $\mathrm{V}_{4} \mathrm{O}_{7}\left(\mathrm{OCH}_{3}\right)^{+}(\mathrm{m} / z$ $=347$ ), $\mathrm{V}_{4} \mathrm{O}_{7}\left(\mathrm{CH}_{3} \mathrm{OH}\right)^{+}$and $\mathrm{V}_{4} \mathrm{O}_{6}(\mathrm{OD})\left(\mathrm{OCH}_{2}\right)^{+}$(both $\mathrm{m} / \mathrm{z}=$ 348), $\mathrm{V}_{4} \mathrm{O}_{8}\left(\mathrm{OCH}_{3}\right)^{+}(\mathrm{m} / \mathrm{z}=363)$, and $\mathrm{V}_{4} \mathrm{O}_{7}(\mathrm{OD})\left(\mathrm{CH}_{3} \mathrm{OH}\right)^{+}(\mathrm{m} / \mathrm{z}$ $=366$ ), which are highlighted in black in Figure $4 \mathrm{a}$. The most abundant product, $\mathrm{V}_{4} \mathrm{O}_{7}\left(\mathrm{OCH}_{3}\right)^{+}$, results from the elimination of $\mathrm{HDO}$ upon reaction with $\mathrm{CH}_{3} \mathrm{OH}$. The isobaric products $\mathrm{V}_{4} \mathrm{O}_{7}\left(\mathrm{CH}_{3} \mathrm{OH}\right)^{+}$and $\mathrm{V}_{4} \mathrm{O}_{6}(\mathrm{OD})\left(\mathrm{OCH}_{2}\right)^{+}$are due to eliminations of $\mathrm{OD}$ and $\mathrm{H}_{2} \mathrm{O}$, respectively, $\mathrm{V}_{4} \mathrm{O}_{8}\left(\mathrm{OCH}_{3}\right)^{+}$is due to dehydrogenation (loss of $\mathrm{HD}$ ), and $\mathrm{V}_{4} \mathrm{O}_{7}(\mathrm{OD})\left(\mathrm{CH}_{3} \mathrm{OH}\right)^{+}$corresponds to the formal adduct. The formation of $\mathrm{m} / z=347$ as the main product in the IMR with $\mathrm{CH}_{3} \mathrm{OD}$ (Figure 4c) demonstrates the $\mathrm{O}-\mathrm{H}$ bond activation of methanol, and we thus propose formation of the methoxo cluster $\mathrm{V}_{4} \mathrm{O}_{7}\left(\mathrm{OCH}_{3}\right)^{+}$, which is consistent with the data for $\mathrm{CH}_{3}{ }^{18} \mathrm{OH}$ and $\mathrm{CH}_{3} \mathrm{OD}$ (Figure 4b,d). Judging from the reactions with $\mathrm{CH}_{3} \mathrm{OD}$ and $\mathrm{CD}_{3} \mathrm{OD}$ (Figure $4 \mathrm{c}, \mathrm{d})$, the expulsion of an OD radical is substantiated, whereas 
formation of $\mathrm{V}_{4} \mathrm{O}_{6}(\mathrm{OD})\left(\mathrm{OCH}_{2}\right)^{+}$is neither confirmed nor disproved by labeling experiments because of isobaric mass interferences with other product ions. ${ }^{35}$ The product ion at $\mathrm{m} / \mathrm{z}$ $=379$ in Figure $4 \mathrm{a}$ is attributed to the association of methanol with the primary ionic product $\mathrm{V}_{4} \mathrm{O}_{7}\left(\mathrm{OCH}_{3}\right)^{+}$to produce $\mathrm{V}_{4} \mathrm{O}_{7}\left(\mathrm{OCH}_{3}\right)\left(\mathrm{CH}_{3} \mathrm{OH}\right)^{+}$. As supported by labeling experiments, $\mathrm{V}_{4} \mathrm{O}_{6}\left(\mathrm{OCH}_{3}\right)_{2}{ }^{+}(\mathrm{m} / \mathrm{z}=362), \mathrm{V}_{m} \mathrm{O}_{n-2}(\mathrm{OD})\left(\mathrm{OCH}_{3}\right)_{2}{ }^{+}(\mathrm{m} / \mathrm{z}=$ $380)$, and $\mathrm{V}_{m} \mathrm{O}_{n-2}\left(\mathrm{OCH}_{3}\right)_{3}{ }^{+}(\mathrm{m} / z=393)$ result via elimination of water upon consecutive reactions of methanol with the primary reaction products $\mathrm{V}_{4} \mathrm{O}_{7}\left(\mathrm{CH}_{3} \mathrm{OH}\right)^{+}(\mathrm{m} / \mathrm{z}=347)$ and $\mathrm{V}_{4} \mathrm{O}_{7}(\mathrm{OD})\left(\mathrm{CH}_{3} \mathrm{OH}\right)^{+}(\mathrm{m} / \mathrm{z}=366)$ and the secondary reaction product $\mathrm{V}_{4} \mathrm{O}_{7}\left(\mathrm{OCH}_{3}\right)\left(\mathrm{CH}_{3} \mathrm{OH}\right)^{+}(\mathrm{m} / z=379)$, respectively.

\section{Conclusions}

Oxidative dehydrogenation $(\mathrm{ODH})$ of methanol by gaseous vanadium oxide cluster cations $\mathrm{V}_{m} \mathrm{O}_{n}{ }^{+}$follows various reaction scenarios: (i) A net oxygen-atom transfer from the cluster to methanol is suggested to yield $\mathrm{CH}_{2} \mathrm{O}+\mathrm{H}_{2} \mathrm{O}$ as the neutral products (ODH1). (ii) Formal uptake of dihydrogen leads to the corresponding $\mathrm{V}_{m} \mathrm{O}_{n-2}(\mathrm{OH})_{2}{ }^{+}$species together with neutral formaldehyde (ODH2). (iii) Loss of water from the cluster can take place after the addition of methanol (ODH3). (iv) $\mathrm{C}-\mathrm{H}$ bond activation of methanol leads to the release of neutral dihydrogen with formaldehyde remaining bound to the cluster ion (DH). The reactivity trends observed for these four types of dehydrogenation suggest a relationship between the formal oxidation states of the vanadium oxide clusters and their reactivities in that $\mathrm{ODH}$ is favored for those clusters having higher formal oxidation states of vanadium. In contrast, $\mathrm{VO}^{+}$ is almost the only cluster cation that exhibits DH activity. Irrespective of the valence state, oxovanadium hydroxide clusters $\mathrm{V}_{m} \mathrm{O}_{n-1}(\mathrm{OH})^{+}$are much less, if not entirely, unreactive with regard to $\mathrm{C}-\mathrm{H}$ bond activation of methanol, which is, in part, due to an efficiently competing condensation reaction, in the course of which the hydroxo clusters $\mathrm{V}_{m} \mathrm{O}_{n-1}(\mathrm{OH})^{+}$are converted to the corresponding methoxo species $\mathrm{V}_{m} \mathrm{O}_{n-1}\left(\mathrm{OCH}_{3}\right)^{+}$ concomitant with loss of neutral water.

Acknowledgment. Financial support from the Deutsche Forschungsgemeinschaft (SFB 546) and the Fonds der Chemischen Industrie is gratefully acknowledged. This work is dedicated to George A. Olah on the occasion of his 80th birthday.

\section{References and Notes}

(1) (a) Olah, G. A.; Goeppert, A.; Prakash, G. K. S. Beyond Oil and Gas: The Methanol Economy; Wiley-VCH: Weinheim, Germany, 2006. (b) Armaroli, N; Balzani, V. Angew. Chem. 2006, 119, 52-67; Angew. Chem., Int. Ed. 2007, 46, 52-66.

(2) Döbler, J.; Pritzsche, M.; Sauer, J. J. Am. Chem. Soc. 2005, 127, 10861-10868.

(3) Boulet, P.; Baiker, A.; Chermette, H.; Gilardoni, F.; Volta, J.-C.; Weber, J. J. Phys. Chem. B 2002, 106, 9659-9667.

(4) (a) Fielicke, A.; Mitric, R.; Meijer, G.; Bonacic-Koutecky, V.; von Helden, G. J. Am. Chem. Soc. 2003, 125, 15716-15717. (b) Justes, D. R.; Mitric, R.; Moore, N. A.; Bonacic-Koutecky, V.; Castleman, A. W., Jr. J. Am. Chem. Soc. 2003, 125, 6289-6299. (c) Moore, N. A.; Mitric, R.; Justes, D. R.; Bonacic-Koutecky, V.; Castleman, A. W., Jr. J. Phys. Chem. B 2006, $110,3015-3022$.

(5) (a) Engeser, M.; Schröder, D.; Schwarz, H. Chem. Eur. J. 2005, 11, 5975-5987. (b) Schröder, D.; Engeser, M.; Schwarz, H.; Rosenthal, E. C. E.; Döbler, J.; Sauer, J. Inorg. Chem. 2006, 16, 6235-6245.

(6) Justes, D. R.; Moore, N. A.; Castleman, A. W., Jr. J. Phys. Chem. B 2004, 108, 3855-3862.

(7) (a) Cao, Y.; Zhao, X.; Xin, B.; Xiong, S.; Tang, Z. J. Mol. Struct. (THEOCHEM) 2004, 683, 141-146. (b) Cao, Y.; Zhao, X.; Xin, B.; Xiong, S.; Tang, Z. J. Mol. Struct. (THEOCHEM) 2005, 724, 229-230.
(8) (a) Feng, T.; Vohs, J. M. J. Catal. 2004, 221, 619-629. (b) Feng, T.; Vohs, J. M. J. Phys. Chem. B 2005, 109, 2120-2127.

(9) (a) Sambeth, J.; Gambaro, L.; Thomas, H. Latin Am. Appl. Res. 1994, 24, 241-245. (b) Sambeth, J.; Gambaro, L.; Thomas, H. Adsorpt. Sci. Technol. 1995, 12, 171-180. (c) Sambeth, J. E.; Centeno, M. A.; Paul, A.; Briand, L. E.; Thomas, H. J.; Odriozola, J. A. J. Mol. Catal. A: Chem. 2000, 161, 89-97. (d) Gambaro, L. A. J. Mol. Catal. A: Chem. 2004, 214, 287-291.

(10) Burcham, L. J.; Wachs, I. E. Catal. Today 1999, 49, 467-484.

(11) Waters, T.; Khairallah, G. N.; Wimala, S. A. S. Y.; Ang, Y. C.; O'Hair, R. A. J.; Wedd, A. G. Chem. Commun. 2006, 4503-4505.

(12) (a) Bell, R. C.; Zemski, K. A.; Kerns, K. P.; Denkg, H. T.; Castleman, A. W., Jr. J. Phys. Chem. A 1998, 102, 1733-1742. (b) Bell, R. C.; Castleman, A. W., Jr. J. Phys. Chem. A 2002, 106, 9893-9899.

(13) Feyel, S.; Schröder, D.; Schwarz, H. J. Phys. Chem. A 2006, 110 , 2647-2654.

(14) (a) Schröder, D.; Weiske, T.; Schwarz, H. Int. J. Mass Spectrom. 2002, 219, 729-738. (b) Trage, C.; Schröder, D.; Schwarz, H. Chem. Eur. J. 2005, 11, 619-627.

(15) (a) Spandl, J.; Daniel, C.; Brudgam, I.; Hartl, H. Angew. Chem. 2003, 115, 1195-1198; Angew. Chem., Int. Ed. 2003, 42, 1163-1166. (b) Daniel, C.; Hartl, H. J. Am. Chem. Soc. 2005, 127, 13978-13987.

(16) Schröder, D.; Engeser, M.; Brönstrup, M.; Daniel, C.; Spandl, J.; Hartl, H. Int. J. Mass Spectrom. 2003, 228, 743-757.

(17) Even though the isotope envelopes of medium-sized multiply charged ions can be resolved well with quadrupole-based mass spectrometers, a separation of ions with a mass difference of $\Delta m=m\left(\mathrm{CH}_{3} \mathrm{OH}\right)-$ $m\left(\mathrm{O}_{2}\right)=0.037 \mathrm{amu}$ cannot be achieved. For an example of relatively high mass resolution using a quadrupole setup, see: Roithová, J.; Schröder, D. Phys. Chem. Chem. Phys., in press.

(18) A reviewer asked for the inclusion of the neutral counterpart $\mathrm{V}_{2} \mathrm{O}_{5}{ }^{+}$ in the reactivity screening, which would indeed be interesting for comparison as this species bears an even larger fv of 5.5. Unfortunately, however, the ion with $\mathrm{m} / \mathrm{z}=182$ formed upon ESI of the precursor compound overlaps with isobaric interferences.

(19) A referee correctly commented that the formation of $\mathrm{CH}_{2} \mathrm{O}+\mathrm{H}_{2} \mathrm{O}$ cannot be considered as oxygenation of the neutral substrate. Yet, we classify the reaction as a formal oxygen-atom transfer because of the experimental observable (loss of one oxygen atom from the $\mathrm{V}_{m} \mathrm{O}_{n}{ }^{+}$cluster).

(20) The actual binding situations of the formaldehyde ligands in the cluster ions are unknown, but coordination via the oxygen lone pairs appears most likely; also see refs. 5, 6, 11, and 21 .

(21) Fiedler, A.; Schröder, D.; Schwarz, H.; Tjelta, B. L.; Armentrout, P. B. J. Am. Chem. Soc. 1996, 118, 5047.

(22) NIST Standard Reference Database Number 69; National Institute of Standards and Technology (NIST): Gaithersburg, MD, Jun 2005 release; see http://webbook.nist.gov/chemistry/.

(23) For methods to probe the nature of neutral molecules formed from gaseous ions, see: Schalley, C. A.; Hornung, G.; Schröder, D.; Schwarz, H. Chem. Soc. Rev. 1998, 27, 91.

(24) Feyel, S.; Döbler, J.; Schröder, D.; Sauer, J.; Schwarz, H. Angew. Chem. 2006, 118, 4797-4801; Angew. Chem., Int. Ed. 2006, 45, 46814685.

(25) See also: Roithová, J.; Schröder, D. Angew. Chem. 2006, 118, 5835-5838; Angew. Chem., Int. Ed. 2006, 45, 5705-5708.

(26) Prüsse, T.; Fiedler, A.; Schwarz, H. J. Am. Chem. Soc. 1991, 113, $8335-8339$

(27) Recombination energy defines the energy of a cation upon recombination with a free electron. In the adiabatic case, $\mathrm{RE}_{\mathrm{a}}$ is identical to the ionization energy $\mathrm{IE}_{\mathrm{a}}$.

(28) Calatayud, M.; Andres, J.; Beltran, A. J. Phys. Chem. A 2001, 105 9760-9775.

(29) For calculated values, see: Sauer, J. Cooperative Projects; SFB 546, Report 1999-2001, Publikationen A4; p 59.

(30) For similar correlations between gas-phase reactivities and ionzation energies, see: (a) Cornehl, H. H.; Wesendrup, R.; Diefenbach, M.; Schwarz, H. Chem. Eur. J. 1997, 3, 1083-1090. (b) Schröder, D.; Trage, C.; Schwarz, H.; Danovich, D.; Shaik, S. Int. J. Mass Spectrom. 2000, 200, 163-173.

(31) See also: (a) Schröder, D.; Jackson, P.; Schwarz, H. Eur. J. Inorg. Chem. 2000, 1171-1175. (b) Jackson, P.; Harvey, J. N.; Schröder, D.; Schwarz, H. Int. J. Mass Spectrom. 2001, 204, 233-245.

(32) For a feature article on this topic, see: Bondybey, V. I.; Beyer, M. K. J. Phys. Chem. A 2001, 105, 951-960.

(33) For an example of such a multilateral study, see: Schröder, D.; Schwarz, H.; Clemmer, D. E.; Chen, Y.-M.; Armentrout, P. B.; Baranov, V. I.; Böhme, D. K. Int. J. Mass Spectrom. Ion Processes 1997, 161, 177.

(34) Khairallah, G. N.; O'Hair, R. A. J.; Bruce, M. I. Dalton Trans. 2006, 30, 3699-3707.

(35) Also because of the low abundance of the channel for $\Delta m=+14$, this possible product ion is accordingly not specified any further in Table 3. 